\title{
Top-of-line corrosion in the presence of carbon dioxide for gas production facilities
}

\author{
Ruslan Vagapov \\ LLC «Gazprom VNIIGAZ», Corporative scientific-technical center of corrosion monitoring and corrosion protection, 142717, Moscow \\ region, Russian Federation
}

\begin{abstract}
Aspects of the development of corrosion processes under conditions of moisture condensation in the gas phase (top-of-line corrosion) in the presence of carbon dioxide, which lead to the formation of local damages, have been investigated. The influence of various factors on corrosion processes under conditions of moisture condensation (top-of-line corrosion) was studied: the acidity of the media (presence of acetic acid), the presence of alcohol (methanol is used in gas production as an inhibitor of hydrate formation), temperature, type of steel and the presence of a weld. In addition to the listed factors, the moisture content in the gas is the determining factor for the development of this type of corrosion under $\mathrm{CO}_{2}$ conditions. The rate of development of corrosion processes depends on the amount and composition of the liquid condensing on the metal surface. The rate of local carbon dioxide corrosion at top-of-line corrosion can reach several $\mathrm{mm} /$ year.
\end{abstract}

\section{Introduction}

In a gas pipeline, corrosion may occur [1]:

- in the lower part of the pipe when moisture accumulates (bottom-of-line corrosion, BOL).

- in the upper part of the pipe, moisture condensation (topof-line corrosion, TOL).

- in places of moisture accumulation (cracks, gaps, stagnant zones).

Currently, one of the key areas of development of the resource base of hydrocarbons (oil, gas, condensate) is the development of fields, which is characterized by a high content of $\mathrm{CO}_{2}$. The presence of $\mathrm{CO}_{2}$ in the produced gas, together with other factors (temperature, moisture, and others.) stimulate the rapid development of corrosion processes, including the most dangerous forms of local corrosion damages [2].

Corrosion due to condensation of moisture is a corrosive case that is characteristic only for the conditions of gas production and transportation. The produced gas is characterized by a certain moisture content in the gas. To create conditions for moisture condensation at a gas production facility, it is necessary that the produced formation fluid has a certain moisture content and at the same time thermobaric conditions are created to release water from the gaseous medium and form its droplets or a thin water layer on the inner surface of the upper component of the pipe.

Corrosion problems caused by generated condensation water can begin as early as the top of the well (pipe tubing), when the produced gas, as it is lifted, moves from reservoir pressure and temperature to lower parameters at the wellhead, becoming oversaturated with water vapor. Conditions for condensation of moisture in the gas phase and the occurrence of corrosion in it can also be created at facilities for processing the produced gas, where temperature and pressure drops in the presence of corrosive acid gases $\left(\mathrm{CO}_{2}\right.$, etc.) take place. Such potentially dangerous from the point of view of the development of corrosion in a vapor environment are: separators, absorbers, and other equipment, including the regeneration of used chemicals, for example, a hydrate inhibitor (methanol).

The most intense corrosive effect is the so-called TOL corrosion, which is characterized by the localization of the corrosion process with the formation of pits and their clusters [3-4]. TOL corrosion cases have been noted and studied in many gas field conditions: Ormen Lange [5-6], Snøhvit [7].

Our analysis shows [8-9] that TOL corrosion can also occur in the operating conditions of existing Russian fields in the initial sections of the pipeline system. For Russian gas production facilities such TOL corrosion studies are being carried out for the first time. Intensification of TOL corrosion can be caused by various factors: the presence of carboxylic acids (acetic acid), temperature rise, heterogeneity of the steel surface.

\section{TOL corrosion in acidic environments}

Produced hydrocarbons may contain carboxylic acids, which will make the aqueous medium more acidic and increase the corrosion of steel. Carboxylic acids are mainly represented by acetic acid $\left(\mathrm{CH}_{3} \mathrm{COOH}\right)$. TOL corrosion tests have shown that under conditions of

\footnotetext{
* Corresponding author: R_Vagapov@vniigaz.gazprom.ru
} 
moisture condensation in the presence of $\mathrm{CO}_{2}$, the local corrosion rate is $0.32-0.384 \mathrm{~mm} /$ year (Table 1).

Table 1. The rate of general and local corrosion, measured on the same samples under conditions of moisture condensation (distilled water) on samples of carbon steel (grade 20) in the presence of $0,1 \mathrm{MPa} \mathrm{CO}$, temperature $20^{\circ} \mathrm{C}$.

\begin{tabular}{|c|c|c|}
\hline $\begin{array}{c}\text { Concentration } \\
\text { of } \mathbf{C H}_{\mathbf{3}} \mathbf{C O O H}, \\
\mathbf{m g} / \mathbf{l}\end{array}$ & $\begin{array}{c}\text { Rate of } \\
\text { common } \\
\text { corrosion, } \\
\text { mm/year }\end{array}$ & $\begin{array}{c}\text { Rate of local } \\
\text { corrosion, } \\
\text { mm/year }\end{array}$ \\
\hline 0 & 0.02 & $0.32-0.384$ \\
\hline 250 & 0.05 & $0.373-0.527$ \\
\hline 1000 & 0.05 & $0.81-1.015$ \\
\hline
\end{tabular}

The addition of $\mathrm{CH}_{3} \mathrm{COOH}$ enhances localized corrosion. With an increase in the concentration of $\mathrm{CH}_{3} \mathrm{COOH} 1000 \mathrm{mg} / \mathrm{l}$, corrosion reaches $1 \mathrm{~mm} /$ year. The overall corrosion rate remains at a fairly low level, and localized corrosion develops. A typical appearance of carbon steel samples after the test under moisture condensation is shown on figure 1: local corrosion damages are visible across the sample surface

\section{$\mathrm{CH}_{3} \mathrm{COOH}$}

$0 \mathrm{mg} / \mathrm{l}$

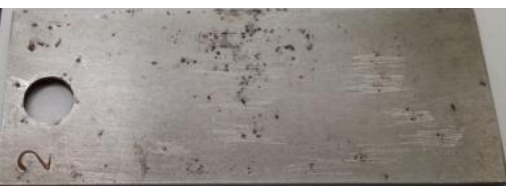

$250 \mathrm{mg} / 1$

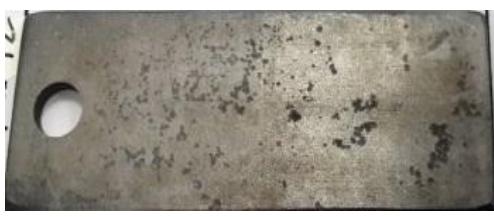

$1000 \mathrm{mg} / 1$

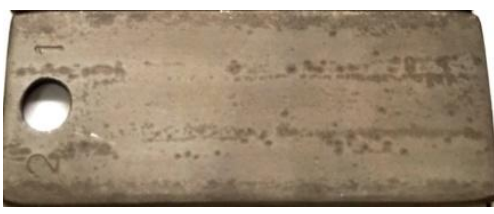

Fig. 1. View of steel samples after testing under conditions of moisture condensation in the presence of $\mathrm{CO}_{2}$ and $\mathrm{CH}_{3} \mathrm{COOH}$.

The study of TOL corrosion by the authors [10] in the presence of $\mathrm{CO}_{2}$ also showed a significant intensification of corrosion with the addition of $\mathrm{CH}_{3} \mathrm{COOH}$.

The resulting corrosion products (iron carbonates) can have a certain protective effect, which is reduced in acidic conditions. The addition of $\mathrm{CH}_{3} \mathrm{COOH}$ shifts the $\mathrm{pH}$ in the condensed moisture film to the region of more acidic values, at which the corrosion products dissolve.

\section{TOL corrosion in water-alcohol solution}

Under the operating conditions of gas production facilities, the liquid phase is often represented by a wateralcohol solution due to the use of methanol as an inhibitor of hydrate formation.

Figure 2 shows data from TOL corrosion tests in $10 \%$ alcohol solution in the presence of $\mathrm{CO}_{2}$. Two types of steel were tested: carbon grade steel 20 and low-alloy $09 \mathrm{Mn} 2 \mathrm{Si}$. The figures show: the average local corrosion rate over all measured values $(K$ (loc.med.)) and the maximum recorded values ( $\mathrm{K}$ (loc.max)).
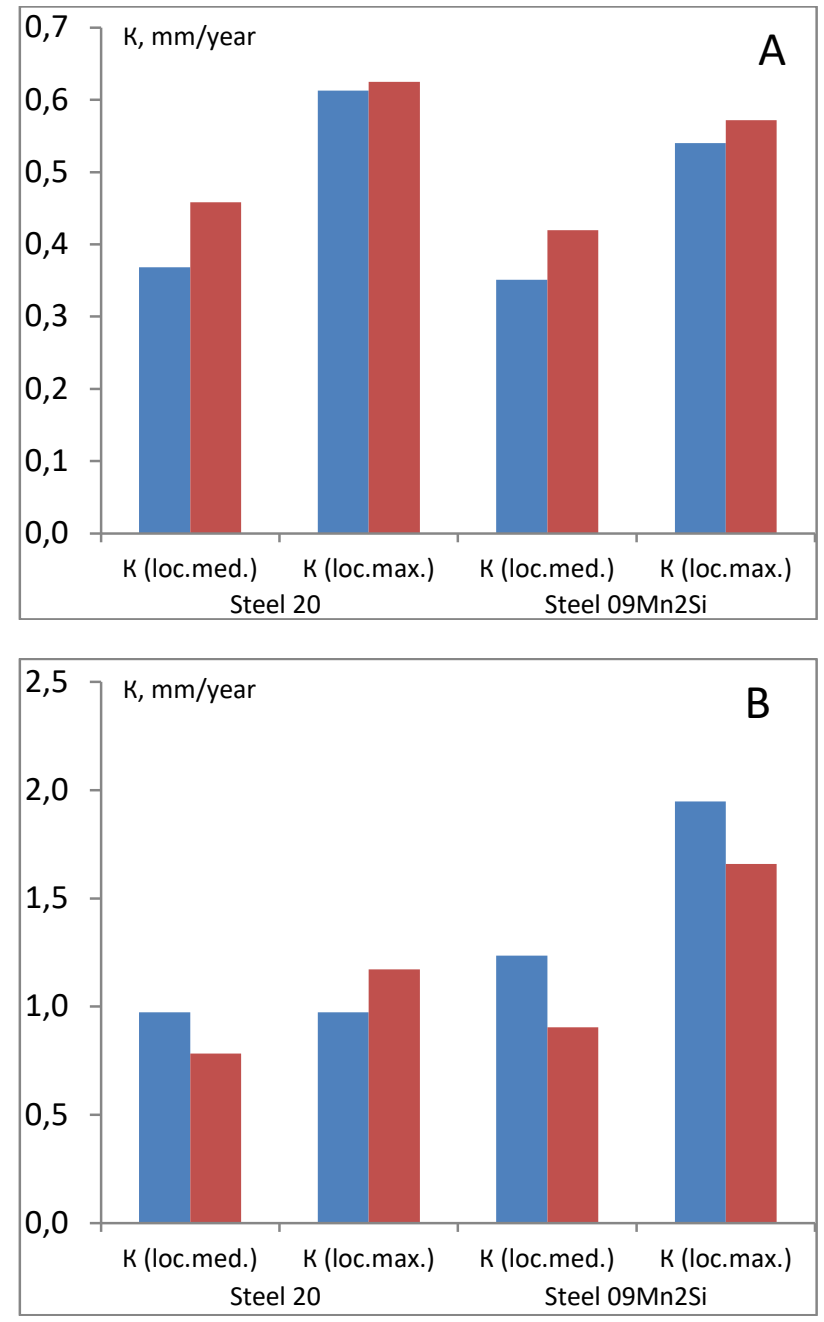

Fig. 2. The rate of local corrosion, measured under conditions of moisture (water:alcohol) condensation on samples of carbon steel (grade 20 and $09 \mathrm{Mn} 2 \mathrm{Si}$ ) in the presence of $0,1 \mathrm{MPa} \mathrm{CO}_{2}$, temperature $20^{\circ}$ и $50^{\circ} \mathrm{C}$ : A $-20^{\circ} \mathrm{C} ; \mathrm{B}-50^{\circ} \mathrm{C}$.

Tests at $20^{\circ} \mathrm{C}$ show (Figure $2 \mathrm{~A}$ ) that $\mathrm{K}$ (loc.med.) is in the range of 0.3 to $0.5 \mathrm{~mm} /$ year. The $\mathrm{K}$ (loc.max) value reaches $0.5-0.6 \mathrm{~mm} /$ year. For an elevated temperature $\left(50^{\circ} \mathrm{C}\right)$ of the test medium: $\mathrm{K}$ (loc.med.) reaches 1.0 $\mathrm{mm} /$ year and $\mathrm{K}$ (loc.max) ranges from 1.0 to $2.0 \mathrm{~mm} /$ year. With an increase in the temperature difference, more liquid condenses on the surface of the steel, which leads to an increase in local corrosion.

It is known that a distinctive feature and a necessity for the development of TOL corrosion in the presence of 
$\mathrm{CO}_{2}$ is the presence of a large amount of condensation moisture $[11,12]$. Therefore, it is not surprising that an increase in the amount of liquid condensed on steel (with a decrease from a higher temperature of $50^{\circ} \mathrm{C}$ ) during tests (Figure 2B) leads to a 2-3 times increase in the rate of corrosion processes, including local ones. The local defects themselves become deeper. The development of the corrosion rate can also be affected by an increase in the temperature of the medium up to $50{ }^{\circ} \mathrm{C}$. However, it should be borne in mind that according to the test method $[8,9]$, steel samples are forcibly cooled to the cooler temperature $\left(15^{\circ} \mathrm{C}\right)$ in order to stimulate moisture condensation. At the interface steel surface - condensed liquid, the temperature will be below $50^{\circ} \mathrm{C}$ (air temperature during testing).

\section{TOL corrosion at elevated temperature}

Since the conditions of elevated temperatures are more aggressive and more typical for active gas fields, subsequent TOL corrosion tests were carried out at $50^{\circ} \mathrm{C}$.

Table 2 presents the TOL test data for elevated temperature corrosion in the presence of $\mathrm{CO}_{2}$. Grade steel 20 and pipe tubing steel. The local corrosion rate of grade steel 20 reaches $1.43-1.85 \mathrm{~mm} /$ year (Table 2). Comparison with the test conditions at $20^{\circ} \mathrm{C}(0.32-0.384$ $\mathrm{mm} /$ year, table 1) for the same grade steel 20 shows that the increase in local corrosion is 5-6 times. Even the overall corrosion rate (Table 2 ) at $50^{\circ} \mathrm{C}$ increases to 0.146 $\mathrm{mm} /$ year is $0.32-0.384 \mathrm{~mm} /$ year.

Table 2. The rate of general and local corrosion, measured on the same samples under conditions of moisture condensation (distilled water) on samples of carbon steel in the presence of $0,1 \mathrm{MPa} \mathrm{CO}_{2}$, temperature $50^{\circ} \mathrm{C}$.

\begin{tabular}{|c|c|c|}
\hline $\begin{array}{c}\text { Type of carbon steel } \\
\text { sample }\end{array}$ & $\begin{array}{c}\text { Rate of } \\
\text { common } \\
\text { corrosion } \\
\text { mm/year }\end{array}$ & $\begin{array}{c}\text { Rate of local } \\
\text { corrosion, } \\
\text { mm/year }\end{array}$ \\
\hline Grade steel 20 & 0,146 & $1.43-1.85$ \\
\hline Pipe tubing & 0,124 & $0.79-0.88$ \\
\hline Steel 09Mn2Si & 0.107 & $1.23-1.95$ \\
\hline X65 (weld) & 0,081 & $0.61-1.23$ \\
\hline X65 (parent pipe) & 0,062 & $0.24-0.32$ \\
\hline
\end{tabular}

As mentioned earlier, moisture condensation can already begin in the pipe tubing, and TOL corrosion can occur in its upper part. It can be seen (Table 2) that both the general $(0.124 \mathrm{~mm} /$ year $)$ and local $(0.79-0.88$ $\mathrm{mm} /$ year) pipe tubing corrosion rates are high. Pipe tubing steel is non-resistant to corrosion TOL. In [13] it is reported that under extreme conditions (with high operating temperatures in the formation up to $180^{\circ} \mathrm{C}$ ), facts of local corrosion of pipe tubing, made even of corrosion-resistant steel $(13 \% \mathrm{Cr})$, were found in one of the fields. The reasons for this, according to the authors of [13], are the high temperature and condensation of a thin film of moisture with a decrease in temperature as the produced gas moves along the pipe tubing - corrosion was observed in the upper third of the pipe.

Welded seams are important research objects that are most often subject to uneven types of corrosion damage. Usually, the welding material is selected close in composition to the material of the main structure. This is done, among other things, in order to reduce contact corrosion due to the heterogeneity of metals. However, during the heat treatment of the metal during welding, as a rule, there is a change in the composition and properties of the material, which can lead to the appearance of heterogeneity between the parent pipe and the weld, which can cause a corrosion process, including TOL corrosion.

As can be seen from Table 2, the rate of local corrosion, measured by the depth of pitting local defects, of samples from the base metal is $0.24-0.32 \mathrm{~mm} /$ year, while for samples with a welded seam it is significantly higher and reaches $0.61-1.23 \mathrm{~mm} /$ year.

Under the conditions of the weld and its heterogeneity with respect to the parent pipe, the degree of localization of the corrosion process increases. It should also be noted that local corrosion damage (figure 3 ) on specimens with a welded seam, local defects in the form of pits are most concentrated in the weld seam and near-weld zone. An increased concentration of defects and a large depth of defects observed according to the test results indicate an increase in corrosion processes in the weld zone as compared to the parent pipe [14].

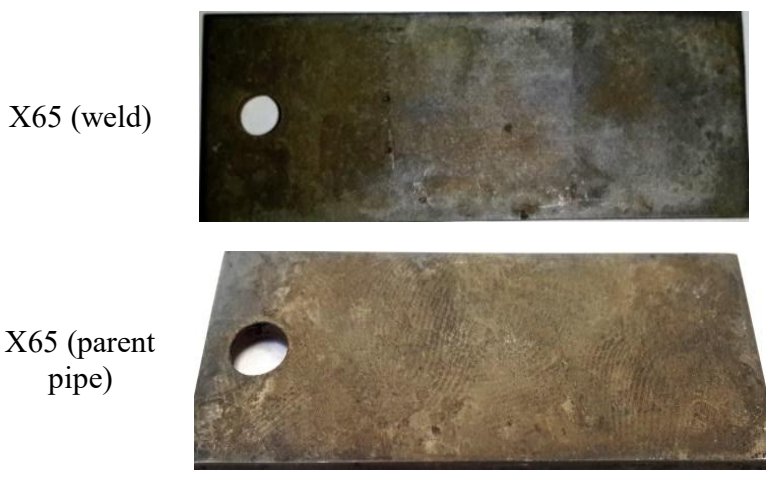

Fig. 3. View of steel samples after testing under conditions of moisture condensation in the presence of $\mathrm{CO}_{2}$ [14].

Carbon dioxide corrosion is characterized mainly by the local development of corrosion processes that appear under conditions of the formation of a thin moisture film on the steel surface - TOL corrosion. At elevated temperatures, when the temperature difference is higher, more moisture condenses on the steel surface, which leads to an increase in the rate of carbon dioxide TOL corrosion of steel [15].

Taking into account the high corrosiveness of the conditions of moisture condensation during carbon dioxide corrosion discovered during the tests, an 
important aspect is to provide the protection from corrosion in such conditions. The main means of fighting TOL corrosion will be either the selection of a material that is corrosion resistant to localized corrosion, or the use of corrosion inhibitors. The possibilities and effectiveness of using both methods for protection against local carbon dioxide corrosion require an independent assessment and additional investigation.

\section{Conclusion}

- TOL corrosion poses a serious danger to gas production equipment in the presence of corrosive $\mathrm{CO}_{2}$, leading to the formation of local damage. At an elevated temperature of the test air $\left(50^{\circ} \mathrm{C}\right)$, when the temperature gradient between the medium and the surface of the steel sample is higher, more moisture condenses on the surface of the steel. This leads to an increase in the rate of carbon dioxide corrosion by 2-3 times as compared to the rate of corrosion at room temperature $\left(20^{\circ} \mathrm{C}\right)$.

- The tested carbon and low-alloy steels turned out to be unresistant to local corrosion when moisture condensation in a carbon dioxide environment. The addition of alcohol (with a content of up to $10 \%$ ) to the evaporated solution does not affect the decrease in the rate of local corrosion of such steels.

- The presence of low carboxylic acids can increase the rate of formation of localized defects during TOL corrosion. TOL corrosion poses a potentially great danger for welded joints due to their heterogeneity in relation to the parent pipe.

\section{References}

1. D.N. Zapevalov, R.K. Vagapov, E3S Web of Conferences, 121, (2019)

2. D.N. Zapevalov, R.K. Vagapov, K.A. Ibatullin, Science \& Technology in the Gas Industry 3, 59 (2018)

3. M. Singer, Corrosion 73, 1030, (2017)

4. Y.M. Gunaltun, D. Larrey, Oil \& gas journa,l 28 (98), 58, (2000)

5. A. Wilhelmsen, H. Meisingset, S. Moxnes, H. O. Knagenhjelm, Oil \& gas journal 103, 62 (2005)

6. A.M.K. Halvorsen, T.R. Andersen, E.N. Halvorsen, G.P. Kojen, J.I. Skar, C. Biørnstad, H. Fitje, Corrosion, Paper 07313, (2007)

7. O. Hagerup, S. Olsen, Corrosion, Paper 03328, (2003)

8. R.K. Vagapov, D.N. Zapevalov, K.A. Ibatullin, Voprosy Materialovedeniya 1 (101), 163, (2020)

9. R.K. Vagapov, D.N. Zapevalov, Defectoskopiya, 7, 61, (2020)

10. T.R. Andersen, A.M.K. Halvorsen, A. Valle, G.P. Kojen, A. Dugstad, Corrosion, Paper 07312, (2007)

11. M.R. Gregg, A. Sharp, K. Bartrip, Corrosion, Paper 03332, (2003)
12. M.R. Gregg, S. Ramachandran, Corrosion, Paper 04432, (2004)

13. Y. Tomoe, M. Zhimizu, T. Hara, R.H. Hausler Corrosion, Paper 00016, (2000)

14. D.N. Zapevalov, R.K. Vagapov, Testing. Diagnostics 3 (261), 30 (2020)

15. R.K. Vagapov, D.N. Zapevalov, K.A. Ibatullin, Industrial laboratory. Diagnostics of materials, $\mathbf{1 0}$ (86), 23, (2020) 